\title{
THE EFFECT OF BREATHING 100\% OXYGEN ON THE PUL- MONARY ARTERIAL PRESSURE IN PATIENTS WITH PULMONARY TUBERCULOSIS AND MITRAL STENOSIS ${ }^{1}$
}

\author{
BY SIDNEY H. DRESSLER, ${ }^{2}$ N. BALFOUR SLONIM, ${ }^{3}$ OSCAR J. BALCHUM,4 \\ GERALD J. BRONFIN, AND ABE RAVIN

\begin{abstract}
(From the Cardio-Pulmonary Laboratory of the National Jewish Hospital at Denver and the Department of Medicine of the University of Colorado Medical Center, Denver, Colo.)
\end{abstract}

(Submitted for publication August 10, 1951 ; accepted May 14, 1952)

The breathing of anoxic mixtures causes an increase in the pulmonary arterial pressure of animals (1-4) and man (5-7). This effect has been attributed to a local action of the anoxic mixture on the blood vessel walls resulting in a constriction of the pulmonary arterioles and pre-capillaries and an increase in pulmonary arterial pressure. Vagotomy and stellate ganglionectomy do not change the vascular response to the breathing of anoxic mixtures in the cat (1).

The effect of breathing $100 \%$ oxygen on the pulmonary arterial pressure has been investigated in animals $(1,3,4,8)$ but not adequately in man. Euler and Liljestrand (1) found that pure oxygen caused a fall in the pulmonary arterial pressure of cats which did not appear to these investigators to be the result of decreased blood flow, but rather to a dilatation of the pulmonary vasculature. The response to oxygen was not affected by vagotomy and stellate ganglionectomy. Ergotamine, yohimbine, and atropine (9) did not alter the decrease of pulmonary arterial pressure which resulted from oxygen breathing.

This paper reports observations on the effect of breathing $100 \%$ oxygen on the pulmonary arterial pressure of patients with pulmonary tuberculosis and mitral stenosis.

\section{METHODS}

Two groups of patients were studied. One group consisted of 21 individuals with pulmonary tuberculosis who were studied 27 times. These were all patients with

1 Aided by a grant from the Life Insurance Medical Research Fund.

${ }^{2}$ Medical Director of the National Jewish Hospital at Denver.

8 Public Health Service Postdoctorate Research Fellow of the National Heart Institute.

4 Fellow of the National Research Council. moderately and far advanced pulmonary tuberculosis (NTA criteria) whose disease was chiefly unilateral. The second group consisted of $\mathbf{1 7}$ individuals with rheumatic heart disease manifested by mitral stenosis who were studied 25 times.

The morning of the catheterization, the patients received .09 gram of nembutal orally and arrived at the laboratory one hour later in the fasting state. Pulmonary artery catheterization was performed in the usual fashion. A blood sample was taken from the brachial artery for determination of the control oxygen saturation, and pressure-pulse records of the pulmonary arterial pressure were made. When the control pressure level had been established the patient was given $100 \%$ oxygen ${ }^{3}$ by BLB mask for a period of four minutes. In 12 instances pulmonary arterial pressure tracings were made continuously during and for ten to 12 minutes after oxygen administration, but in the majority a record was made only when oxygen had been given for three minutes. A sample of brachial arterial blood was withdrawn at the fourth minute of oxygen administration for determination of oxygen saturation.

Arterial blood samples were analyzed for oxygen content and capacity by the method of Van Slyke and Neill (10), and more recently by the Scholander-Roughton syringe method (11). The pulmonary arterial pressure was recorded with a Hathaway Blood Pressure Control Unit and Oscillograph ${ }^{6}$ and in many instances was simultaneously recorded with a Sanborn Electromanometer connected to the Hathaway Oscillograph. Recordings were calibrated with a mercury manometer after each tracing. The zero point for all pressures was $5 \mathrm{~cm}$. posterior to the sternal angle of Louis with the patient supine. Mean pressures were obtained by planimetric integration of the pressure-pulse contours when the Hathaway Blood Pressure Recording System was used and by electrical integration when the Sanborn Electromanometer was used.

The respiratory pattern as evidenced by rhythmic baseline fluctuation was present in all pressure tracings, except in those of patients with mitral stenosis who had auricular fibrillation. Representative expiratory and inspiratory

- The mean annual barometric pressure in Denver is $628 \mathrm{~mm}$. Hg.

- Type SYBP-1 Blood Pressure Recording System. 
pressure-pulse contours were taken for each measurement, and the average systolic, diastolic and mean values recorded. Only mean pressures were used in the statistical analyses. Measurements of all pressure tracings were rounded to the nearest integer, and five-tenths was rounded to the nearest even integer.

\section{RESULTS}

\section{1) Pulmonary arterial pressure}

Of a total of 52 studies made on patients with pulmonary tuberculosis and mitral stenosis, 43 showed a decrease in pulmonary arterial pressure during oxygen breathing, three showed no change, and six showed slight increases (Tables I, II and III). The decreases ranged from 1 to 18 $\mathrm{mm}$. $\mathrm{Hg}$ systolic, from 1 to $12 \mathrm{~mm}$. $\mathrm{Hg}$ diastolic, and from 1 to $13 \mathrm{~mm}$. $\mathrm{Hg}$ mean.

Out of 27 studies in patients with pulmonary tuberculosis, 22 showed a decrease of pulmonary arterial pressure with oxygen, two showed no change, and three showed slight increases. Where a decrease occurred, the average drop in systolic pressure was $4 \mathrm{~mm}$. $\mathrm{Hg}$ ( $17 \%$ of the control level), the average drop in diastolic pressure was $3 \mathrm{~mm}$. $\mathrm{Hg}$ (33\% of the control level), and the average drop in the mean pressure was $3 \mathrm{~mm}$. $\mathrm{Hg}$ (19\% of the control level). In the three instances where an increase was noted, the rise averaged $2 \mathrm{~mm}$. $\mathrm{Hg}$ systolic, $2 \mathrm{~mm}$. $\mathrm{Hg}$ diastolic, and $1 \mathrm{~mm}$. $\mathrm{Hg}$ mean.

Out of 25 studies in patients with mitral stenosis, 21 showed a decrease in pulmonary arterial pressure with oxygen, one showed no change, and three showed slight increases. Where a decrease occurred, the average drop in systolic pressure was $7 \mathrm{~mm}$. $\mathrm{Hg}$ ( $16 \%$ of the control level), the average drop in diastolic pressure was $5 \mathrm{~mm}$. $\mathrm{Hg}$ ( $21 \%$ of the control level), and the average drop in the mean pressure was $4 \mathrm{~mm}$. $\mathrm{Hg}$ (13\% of the control level). In the three instances where an increase was noted, the rise averaged $2 \mathrm{~mm}$. Hg systolic, $1 \mathrm{~mm}$. $\mathrm{Hg}$ diastolic, and $1 \mathrm{~mm}$. $\mathrm{Hg}$ mean.

TABLE I

The effect of breathing $100 \%$ oxygen on pulmonary arterial pressure, pulse rate, and arterial saturation in patients with pulmonary tuberculosis

\begin{tabular}{|c|c|c|c|c|c|c|c|c|c|c|c|c|c|c|c|}
\hline \multirow{2}{*}{ Patient } & \multicolumn{9}{|c|}{ Pulmonary arterial pressure* } & \multicolumn{3}{|c|}{ Pulse rate } & \multicolumn{3}{|c|}{ Arterial saturation } \\
\hline & \multicolumn{3}{|c|}{ Control } & \multicolumn{3}{|c|}{ Oxygen } & \multicolumn{3}{|c|}{ Change } & Control & Oxygen & Change & Control & Oxygen & Change \\
\hline $\begin{array}{l}\text { AFD } \\
\text { KLW } \\
\text { BJP } \\
\text { BJP } \\
\text { LMW } \\
\text { LMW } \\
\text { DCL } \\
\text { DCL } \\
\text { RRS } \\
\text { MV } \\
\text { RL } \\
\text { RL } \\
\text { TR } \\
\text { TR } \\
\text { LS } \\
\text { FG } \\
\text { AC } \\
\text { FJG } \\
\text { EV } \\
\text { LEV } \\
\text { AG } \\
\text { FVG } \\
\text { VFP } \\
\text { VFP } \\
\text { GAR } \\
\text { JFA } \\
\text { IN }\end{array}$ & $\begin{array}{c}S \\
23 \\
28 \\
24 \\
21 \\
23 \\
26 \\
15 \\
16 \\
12 \\
22 \\
16 \\
24 \\
24 \\
26 \\
28 \\
30 \\
20 \\
26 \\
22 \\
24 \\
22 \\
39 \\
25 \\
20 \\
20 \\
14 \\
30\end{array}$ & $\begin{array}{r}D \\
10 \\
12 \\
7 \\
8 \\
7 \\
8 \\
4 \\
6 \\
8 \\
6 \\
7 \\
3 \\
8 \\
8 \\
13 \\
7 \\
6 \\
9 \\
10 \\
9 \\
14 \\
24 \\
6 \\
6 \\
6 \\
4 \\
10\end{array}$ & $\begin{array}{r}M \\
16 \\
20 \\
18 \\
15 \\
15 \\
16 \\
10 \\
12 \\
10 \\
14 \\
10 \\
15 \\
16 \\
15 \\
20 \\
16 \\
14 \\
18 \\
16 \\
16 \\
18 \\
30 \\
14 \\
13 \\
12 \\
8 \\
17\end{array}$ & $\begin{array}{c}S \\
16 \\
23 \\
23 \\
17 \\
26 \\
28 \\
12 \\
14 \\
12 \\
15 \\
12 \\
18 \\
18 \\
22 \\
26 \\
24 \\
21 \\
22 \\
20 \\
20 \\
18 \\
28 \\
22 \\
20 \\
21 \\
12 \\
26\end{array}$ & $\begin{array}{r}D \\
6 \\
10 \\
8 \\
7 \\
9 \\
8 \\
4 \\
8 \\
4 \\
2 \\
4 \\
2 \\
4 \\
6 \\
8 \\
6 \\
6 \\
8 \\
8 \\
6 \\
8 \\
16 \\
4 \\
6 \\
4 \\
4 \\
8\end{array}$ & $\begin{array}{r}M \\
10 \\
16 \\
16 \\
13 \\
16 \\
17 \\
9 \\
10 \\
8 \\
11 \\
8 \\
12 \\
11 \\
15 \\
18 \\
14 \\
14 \\
16 \\
12 \\
13 \\
12 \\
21 \\
12 \\
12 \\
10 \\
9 \\
14\end{array}$ & $\begin{array}{l}5 \\
-7 \\
=5 \\
=1 \\
=4 \\
+3 \\
+2 \\
=3 \\
-2 \\
-7 \\
=4 \\
-6 \\
-6 \\
=4 \\
=2 \\
-6 \\
\pm 1 \\
-4 \\
-2 \\
-4 \\
-11 \\
-3 \\
01 \\
\pm 2 \\
-4\end{array}$ & $\begin{array}{r}D \\
-4 \\
-2 \\
+1 \\
-1 \\
+2 \\
0 \\
0 \\
+2 \\
-4 \\
-4 \\
-3 \\
-1 \\
-4 \\
-2 \\
-5 \\
-1 \\
0 \\
-1 \\
-2 \\
-3 \\
-6 \\
-8 \\
-2 \\
0 \\
-2 \\
0 \\
-2\end{array}$ & $\begin{array}{l}M \\
-6 \\
-4 \\
-2 \\
-2 \\
+1 \\
+1 \\
-1 \\
-2 \\
-2 \\
-3 \\
-2 \\
-3 \\
-5 \\
0 \\
-2 \\
-2 \\
0 \\
-2 \\
-4 \\
-3 \\
-6 \\
-9 \\
-2 \\
-1 \\
-2 \\
+1 \\
-3\end{array}$ & $\begin{array}{r}95 \\
115 \\
95 \\
100 \\
80 \\
85 \\
75 \\
85 \\
92 \\
85 \\
100 \\
90 \\
105 \\
85 \\
95 \\
115 \\
80 \\
95 \\
100 \\
90 \\
85 \\
95 \\
82 \\
97 \\
80 \\
107 \\
82 \\
\end{array}$ & $\begin{array}{r}80 \\
95 \\
90 \\
90 \\
80 \\
80 \\
75 \\
72 \\
90 \\
85 \\
100 \\
85 \\
85 \\
75 \\
80 \\
105 \\
70 \\
88 \\
100 \\
100 \\
75 \\
92 \\
72 \\
95 \\
72 \\
100 \\
72 \\
\end{array}$ & $\begin{array}{r}-15 \\
-20 \\
-5 \\
-10 \\
0 \\
-5 \\
0 \\
-13 \\
-2 \\
0 \\
0 \\
-5 \\
-20 \\
-10 \\
-15 \\
-10 \\
-10 \\
-7 \\
0 \\
+10 \\
-10 \\
-3 \\
-10 \\
-2 \\
-8 \\
-7 \\
-10 \\
\end{array}$ & $\begin{array}{l}93 \\
94 \\
91 \\
91 \\
95 \\
88 \\
96 \\
88 \\
92 \\
93 \\
90 \\
90 \\
93 \\
93 \\
90 \\
91 \\
90 \\
90 \\
85 \\
94 \\
94 \\
84 \\
87 \\
92 \\
90 \\
92 \\
88 \\
\end{array}$ & $\begin{array}{r}98 \\
100 \\
99 \\
92 \\
99 \\
98 \\
99 \\
94 \\
97 \\
\\
100 \\
98 \\
98 \\
99 \\
98 \\
96 \\
97 \\
98 \\
96 \\
97 \\
98 \\
95 \\
95 \\
98 \\
98 \\
94 \\
98 \\
\end{array}$ & $\begin{array}{l}+5 \\
+6 \\
+8 \\
+1 \\
+4 \\
+10 \\
+3 \\
+6 \\
+5 \\
+10 \\
+8 \\
+5 \\
+6 \\
+8 \\
+5 \\
+7 \\
+8 \\
+11 \\
+3 \\
+4 \\
+11 \\
+8 \\
+6 \\
+8 \\
+2 \\
+10 \\
\end{array}$ \\
\hline Average & 23 & 8 & 15 & 20 & 6 & 13 & -3 & -2 & -2 & 92 & 85 & -7 & 91 & 97 & +6 \\
\hline
\end{tabular}

* $\mathrm{S}=$ systolic, $\mathrm{D}=$ diastolic, and $\mathrm{M}=$ mean. 
TABLE II

The effect of breathing $100 \%$ oxygen on the pulmonary arterial pressure, pulse rate, and arterial saturation in patients with mitral stenosis

\begin{tabular}{|c|c|c|c|c|c|c|c|c|c|c|c|c|c|c|c|}
\hline \multirow{2}{*}{ Patic } & \multicolumn{9}{|c|}{ Pulmonary arterial pressure* } & \multicolumn{3}{|c|}{ Pulse rate } & \multicolumn{3}{|c|}{ Arterial saturation } \\
\hline & \multicolumn{3}{|c|}{ Control } & \multicolumn{3}{|c|}{ Oxygen } & \multicolumn{3}{|c|}{ Change } & Control & Oxygen & Change & Control & Oxygen & Change \\
\hline $\begin{array}{l}\text { LHS } † \\
\text { LHS } \\
\text { RJD } \\
\text { RJD } \\
\text { HMW } \\
\text { CFW } \\
\text { CFW } \\
\text { HJS } \\
\text { TB } \ddagger \\
\text { TB } \ddagger \\
\text { ND } \\
\text { ERH } \\
\text { ERH } \\
\text { BLP } \\
\text { CLR } \\
\text { CLR } \\
\text { GER } \\
\text { GER } \\
\text { MTD } \\
\text { MTD } \\
\text { EMB } \\
\text { EBW } \\
\text { BLM } \ddagger \\
\text { FCD } \ddagger \\
\text { EM } \ddagger\end{array}$ & $\begin{array}{c}S \\
26 \\
38 \\
41 \\
34 \\
33 \\
58 \\
49 \\
72 \\
32 \\
44 \\
64 \\
21 \\
41 \\
40 \\
52 \\
48 \\
54 \\
31 \\
35 \\
42 \\
40 \\
29 \\
39 \\
53 \\
68\end{array}$ & $\begin{array}{c}D \\
10 \\
16 \\
22 \\
12 \\
15 \\
28 \\
34 \\
32 \\
20 \\
22 \\
24 \\
6 \\
13 \\
18 \\
26 \\
22 \\
32 \\
13 \\
16 \\
18 \\
13 \\
10 \\
12 \\
24 \\
29\end{array}$ & $\begin{array}{l}M \\
17 \\
26 \\
28 \\
21 \\
21 \\
40 \\
38 \\
52 \\
24 \\
31 \\
33 \\
15 \\
26 \\
29 \\
34 \\
33 \\
41 \\
22 \\
24 \\
25 \\
26 \\
17 \\
24 \\
37 \\
36\end{array}$ & $\begin{array}{c}S \\
28 \\
34 \\
40 \\
433 \\
30 \\
44 \\
34 \\
62 \\
29 \\
38 \\
22 \\
22 \\
35 \\
35 \\
48 \\
41 \\
36 \\
33 \\
32 \\
27 \\
35 \\
26 \\
36 \\
48 \\
62\end{array}$ & $\begin{array}{r}D \\
12 \\
15 \\
20 \\
12 \\
15 \\
16 \\
24 \\
30 \\
14 \\
15 \\
\\
6 \\
12 \\
16 \\
20 \\
22 \\
22 \\
14 \\
16 \\
8 \\
14 \\
10 \\
12 \\
22 \\
28\end{array}$ & $\begin{array}{l}M \\
19 \\
25 \\
26 \\
20 \\
19 \\
27 \\
30 \\
46 \\
22 \\
26 \\
26 \\
14 \\
25 \\
27 \\
32 \\
29 \\
29 \\
23 \\
23 \\
17 \\
24 \\
18 \\
24 \\
32 \\
34\end{array}$ & 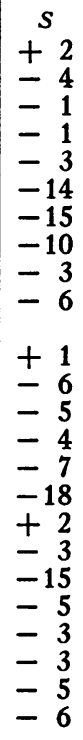 & \begin{tabular}{|r}
$D$ \\
+2 \\
\pm 1 \\
-2 \\
0 \\
0 \\
-12 \\
-10 \\
$=2$ \\
-6 \\
-7 \\
0 \\
-1 \\
-2 \\
-6 \\
0 \\
-10 \\
+1 \\
0 \\
-10 \\
+1 \\
0 \\
0 \\
-2 \\
-1 \\
-1
\end{tabular} & $\begin{array}{l}\quad M \\
+2 \\
\pm 1 \\
=2 \\
=1 \\
=2 \\
-13 \\
=8 \\
=6 \\
=2 \\
=5 \\
=7 \\
=1 \\
=1 \\
=2 \\
=2 \\
=4 \\
-12 \\
\pm 1 \\
=1 \\
=8 \\
=2 \\
+1 \\
0 \\
=5 \\
-2\end{array}$ & $\begin{array}{r}65 \\
55 \\
60 \\
63 \\
58 \\
75 \\
100 \\
82 \\
90 \\
75 \\
87 \\
85 \\
82 \\
90 \\
98 \\
66 \\
90 \\
105 \\
85 \\
64 \\
75 \\
65 \\
80 \\
70 \\
65\end{array}$ & \begin{tabular}{|r}
65 \\
55 \\
55 \\
57 \\
58 \\
50 \\
85 \\
80 \\
82 \\
64 \\
80 \\
90 \\
80 \\
110 \\
96 \\
62 \\
82 \\
95 \\
80 \\
60 \\
65 \\
70 \\
66 \\
57 \\
60
\end{tabular} & $\begin{array}{r}0 \\
0 \\
-5 \\
-6 \\
0 \\
-25 \\
-15 \\
=2 \\
=8 \\
-11 \\
-7 \\
+5 \\
-2 \\
+20 \\
-2 \\
=4 \\
=8 \\
-10 \\
=5 \\
=4 \\
-10 \\
+5 \\
-14 \\
-13 \\
-5\end{array}$ & $\begin{array}{l}87 \\
91 \\
90 \\
93 \\
94 \\
95 \\
86 \\
90 \\
90 \\
89 \\
91 \\
94 \\
90 \\
94 \\
89 \\
88 \\
95 \\
94 \\
88 \\
93 \\
94 \\
88 \\
89 \\
92 \\
93\end{array}$ & $\begin{array}{r}99 \\
98 \\
98 \\
99 \\
98 \\
100 \\
96 \\
98 \\
96 \\
97 \\
97 \\
96 \\
94 \\
99 \\
97 \\
92 \\
100 \\
98 \\
96 \\
93 \\
98 \\
97 \\
94 \\
94 \\
100\end{array}$ & $\begin{array}{l}+12 \\
+7 \\
+8 \\
+6 \\
+4 \\
+5 \\
+10 \\
+8 \\
+6 \\
+8 \\
+6 \\
+2 \\
+4 \\
+5 \\
+8 \\
+4 \\
+5 \\
+4 \\
+8 \\
+0 \\
+4 \\
+99 \\
+5 \\
+2 \\
+7\end{array}$ \\
\hline Average & 43 & 19 & 29 & 37 & 16 & 26 & -6 & $|-3|$ & -3 & 77 & 72 & -5 & 91 & 97 & +6 \\
\hline
\end{tabular}

* $\mathrm{S}=$ systolic, $\mathrm{D}=$ diastolic, and $\mathrm{M}=$ mean. $\dagger$ Auricular flutter. $\ddagger$ Auricular fibrillation.

For the pulmonary tuberculosis group the standard error of the mean of the differences between the mean pulmonary arterial pressures before and during oxygen breathing was determined from standard statistical formulas. ${ }^{7}$ The mean pairdifference divided by the standard error gives a $t$ value of 4.5 . This shows a highly significant difference between the control pulmonary arterial pressure and the pressure during oxygen breathing, since this $t$ value corresponds to a $\mathrm{P}$ of less than .00006 . For the mitral stenosis group the mean pair-difference divided by the standard error gives a $t$ value of 3.9 which corresponds to a $\mathrm{P}$ of less than .0001 .

The results obtained in 12 cases where the pulmonary arterial pressure was recorded continuously during and after oxygen breathing are shown in Figures 1 and 2. In Figure 1 the cases are grouped according to diagnosis and in Figure 2 according to control pressure level. The pressure

${ }^{7}$ Fisher, R. A., Statistical Methods for Research Workers. Oliver \& Boyd, Edinburgh, 1950, 11th ed. decrease is quite apparent at one minute and almost complete at two minutes, with only slight change during the third and fourth minutes. Two minutes after the cessation of oxygen breathing the pressure has shown very little rise, but at six and ten minutes there has been a partial return to the control level.

\section{2) Level of pulmonary arterial pressure and de- gree of change}

There was a definite association between the control mean pulmonary arterial pressure and the degree of its fall during oxygen administration. The regression line of the change in mean pressure on the control pressure for the pulmonary tuberculosis group is given by the equation $\mathrm{Y}=$ $-.35 \mathrm{X}+3.0$, while that for the mitral stenosis group is $\mathrm{Y}=-.31 \mathrm{X}+5.7$. The regression coefficients are very similar for the two groups of patients. Of the patients who showed a decrease in pulmonary arterial pressure with oxygen, the average fall of the 11 with the highest control pres- 
TABLE III

The effect of breathing $100 \%$ oxygen on pulmonary arterial pressure and pulse rate in patients with pulmonary tuberculosis and mitral stenosis

\begin{tabular}{|c|c|c|c|c|c|c|c|c|c|c|c|}
\hline & & & \multicolumn{3}{|c|}{ Pulmonary tuberculosis } & \multicolumn{3}{|c|}{ Mitral stenosis } & \multicolumn{3}{|c|}{ Total } \\
\hline & & & Decrease & Increase & No change & Decrease & Increase & No change & Decrease & Increase & No change \\
\hline \multicolumn{3}{|c|}{$\begin{array}{c}\text { Number of } \\
\text { instances }\end{array}$} & 22 & 3 & 2 & 21 & 3 & 1 & 43 & 6 & 3 \\
\hline \multirow{3}{*}{$\begin{array}{c}\text { Pulmonary } \\
\text { arterial } \\
\text { pressure* }\end{array}$} & \multirow{3}{*}{$\begin{array}{c}\text { Change: } \\
\text { Average } \\
\text { and } \\
\text { Range }\end{array}$} & $\mathbf{s}$ & $\begin{array}{l}-4(17 \%) \\
-1 \text { to }-11\end{array}$ & $\begin{array}{l}+2(8 \%) \\
+1 \text { to }+3\end{array}$ & & $\begin{array}{l}-7(16 \%) \\
-1 \text { to }-18\end{array}$ & $\begin{array}{l}+2(6 \%) \\
+1 \text { to }+2\end{array}$ & & $\begin{array}{l}-5(17 \%) \\
-1 \text { to }-18\end{array}$ & $\begin{array}{l}+2(7 \%) \\
+1 \text { to }+3\end{array}$ & \\
\hline & & $\mathbf{D}$ & $\begin{array}{l}-3(33 \%) \\
-1 \text { to }-8\end{array}$ & $\begin{array}{l}+2(25 \%) \\
+1 \text { to }+2\end{array}$ & & $\begin{array}{l}-5(21 \%) \\
-1 \text { to }-12\end{array}$ & $\begin{array}{l}+1(11 \%) \\
+1 \text { to }+2\end{array}$ & & $\begin{array}{l}-4(27 \%) \\
-1 \text { to }-12\end{array}$ & $\begin{array}{l}+2(18 \%) \\
+1 \text { to }+2 \\
\end{array}$ & \\
\hline & & $\mathbf{M}$ & $\begin{array}{l}-3(19 \%) \\
-1 \text { to }-9\end{array}$ & $\begin{array}{c}+1(8 \%) \\
+1\end{array}$ & & $\begin{array}{l}-4(13 \%) \\
-1 \text { to }-13\end{array}$ & $\begin{array}{l}+1(7 \%) \\
+1 \text { to }+2\end{array}$ & & $\begin{array}{l}-3(16 \%) \\
-1 \text { to }-13\end{array}$ & $\begin{array}{l}+1(8 \%) \\
+1 \text { to }+2\end{array}$ & \\
\hline \multirow{2}{*}{ Pulse rate } & \multicolumn{2}{|c|}{$\begin{array}{c}\text { Number of } \\
\text { instances }\end{array}$} & 18 & 1 & 5 & 17 & 3 & 3 & 35 & 4 & 8 \\
\hline & \multicolumn{2}{|c|}{$\begin{array}{c}\text { Average } \\
\text { change }\end{array}$} & -10 & +10 & & -9 & +10 & & -10 & +10 & \\
\hline
\end{tabular}

$* \mathrm{~S}=$ systolic, $\mathrm{D}=$ diastolic, and $\mathrm{M}=$ mean.

sures was $18 \%$, and the average fall of the 11 with the lowest control pressures was $15 \%$.

The actual drop in pressure in the patients with pulmonary tuberculosis was less than in the mitral stenosis patients, possibly because the control pulmonary arterial pressure was lower. The change in patients with a normal pressure was often of a small degree. However, of the 14 instances where the control pressure was normal $(15 \mathrm{~mm}$. $\mathrm{Hg}$ or less), ten showed a decrease in pressure, two showed no change and two showed increases of 1 $\mathrm{mm}$. $\mathrm{Hg}$ each. Calculations in these 14 instances, however, revealed a statistically significant decrease of the mean pulmonary arterial pressures during oxygen breathing. The $t$ value for this is 3.67 which corresponds to a $\mathrm{P}$ of less than .01 . Thus the observed decreases would occur less often than once in a hundred times by chance alone.

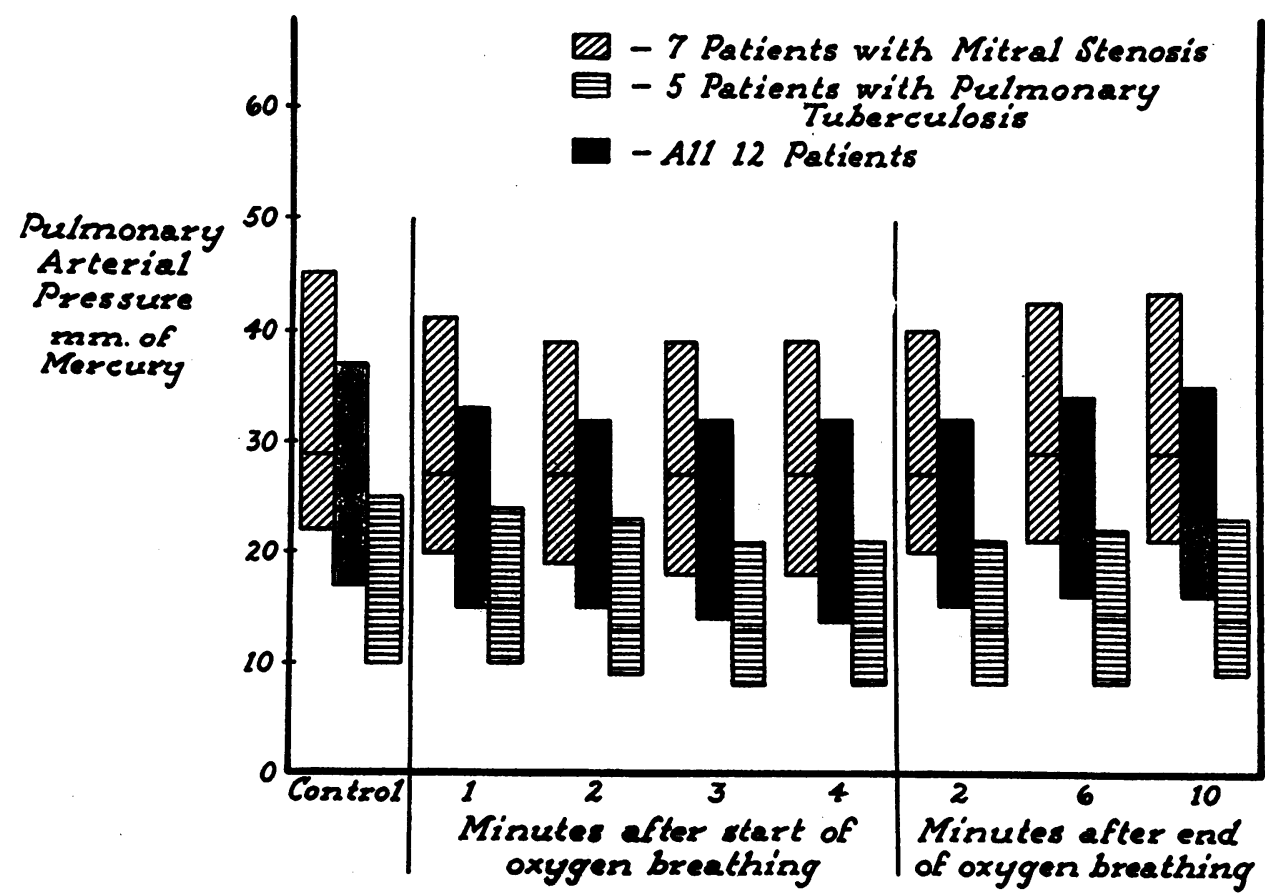

FIG. 1 


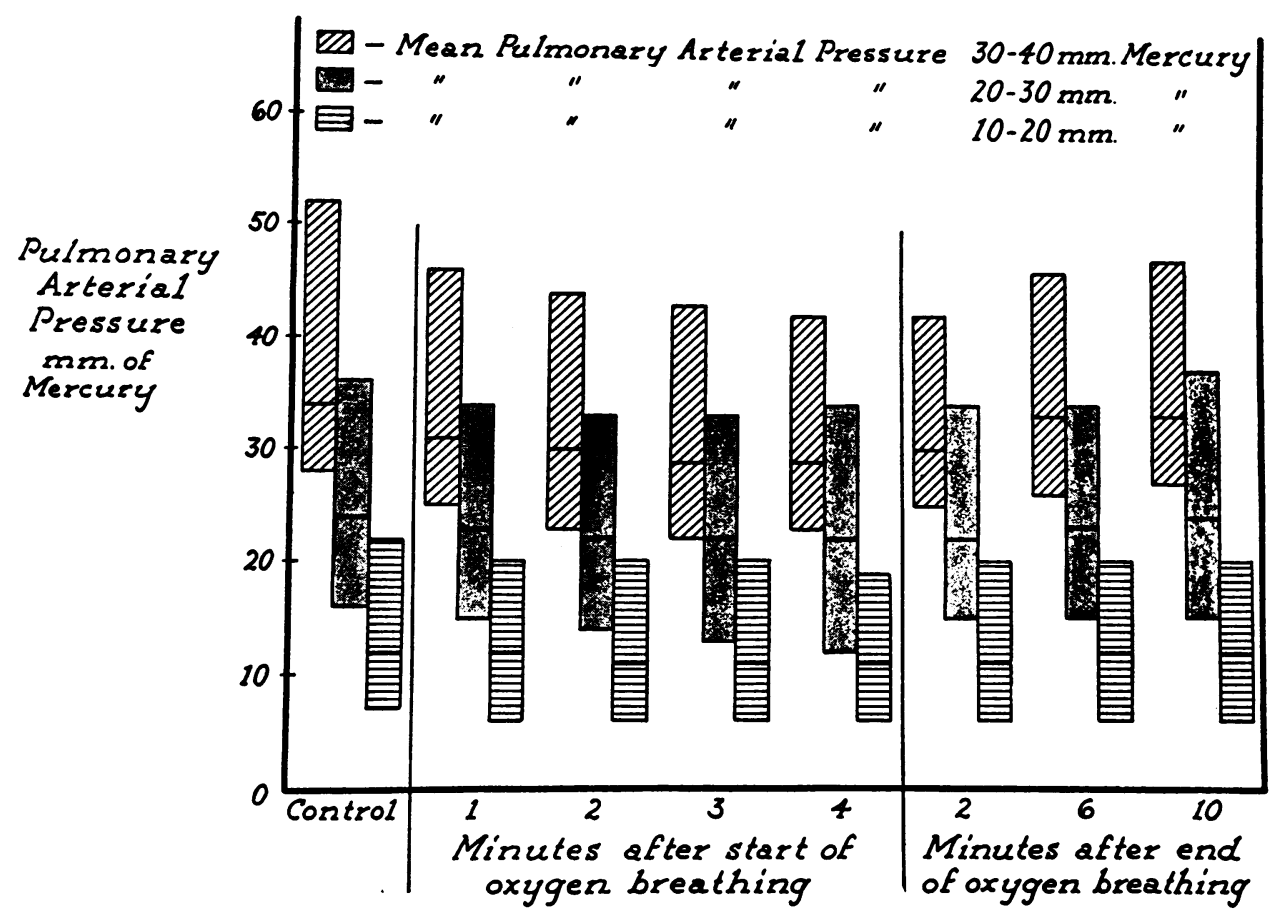

FIG. 2

Although these patients had a normal pulmonary arterial pressure, it should be noted that they had in general rather extensive pulmonary disease.

\section{3) Pulse rate}

The pulse rate decreased together with the mean pulmonary arterial pressure in 34 instances (Tables I, II and III). However, in three instances where the pulse rate increased, the mean pulmonary arterial pressure decreased. In six instances where the pulse rate showed no change, there were decreases in the mean pulmonary arterial pressure. In three instances pulse rate decreases were associated with no change in the mean pulmonary arterial pressure.

\section{4) Arterial saturation}

A study of control arterial oxygen saturations (range from $84 \%$ to $96 \%$ ) and changes in the mean pulmonary arterial pressure resulting from oxygen breathing failed to reveal an appreciable correlation. However, the range of arterial oxygen saturations was not great. It is interesting to note that the patient with the highest mean pulmonary arterial pressure in the pulmonary tuberculosis group had the lowest control arterial saturation and showed the greatest drop in pressure with oxygen.

\section{DISCUSSION}

The data presented indicate that individuals with pulmonary tuberculosis and mitral stenosis at the barometric pressure in Denver show a decrease in pulmonary arterial pressure during oxygen breathing. Such a decrease could be due to: 1) a reduction in the volume of blood flow through the pulmonary vascular bed, 2) a diminution of pulmonary vascular resistance, or 3) a fall of the left atrial and pulmonary venous pressure. A decrease in cardiac output during oxygen breathing in man has been noted by several investigators using the ballistocardiograph (12-14). This decrease has been estimated to be from $10 \%$ to $20 \%$ and is reflected initially by a decrease in pulse rate. It has been reported that during the first five minutes of oxygen breathing, approximately $94 \%$ of the decrease in cardiac output is reflected in a decrease of pulse rate and the remainder is reflected by a decrease of stroke output (12). Although there is some question regarding the validity of absolute values for cardiac output as determined by the ballistocardiograph, it seems 
likely that the changes in output observed during oxygen breathing by this method are valid.

That the pulse rate decreases with oxygen breathing has been frequently noted in both animals and man (15-18) and is evident in the present study. This prompt decrease in pulse rate during oxygen breathing has been attributed to a moderation of tonic chemoreceptor activity (1, $14,19)$. If the decrease in pulse rate seen in these patients were associated with a decreased cardiac output, the change in pulmonary blood flow could be a factor in the fall of the pulmonary arterial pressure. A decrease of pulse rate, however, need not be associated with a decrease of cardiac output, if the stroke output increases. It should be noted that in several instances a decrease in mean pulmonary arterial pressure was associated with no change or even increase in pulse rate.

Euler and Liljestrand did not believe that a change in cardiac output could account for the drop in pulmonary arterial pressure which they obtained, since the change in pressure was greater than that obtained by marked exercise. It has also been shown that in normal individuals exercise of fairly marked degree has little effect on pulmonary arterial pressure (20). Thus it is unlikely that a small change in cardiac output would be an important factor in decreasing the pulmonary arterial pressure. However, until the cardiac output has been measured by more exact methods in both animals and man, the part played by changes in pulmonary blood flow cannot be fully evaluated. In studies on the effect of acute anoxia on the human pulmonary circulation, the cardiac output has not been found to show a definite change $(5,7)$, and certainly has not changed enough to explain the pulmonary arterial pressure rise.

Because Euler and Liljestrand did not believe that changes in cardiac output could account for the drop in pressure, and because they and others found that the drop occurred in the absence of the nerve supply, they postulated that the fall in pressure was due to a direct action of oxygen on the pulmonary vasculature producing vasodilatation. Our experience with one patient may indicate that in man, as well as in animals, the drop in pulmonary arterial pressure is not dependent upon an intact nerve supply. This patient had bronchial asthma (not included in tables or figures), and had previously undergone bilateral pulmonary hilar stripping and bilateral stellate ganglionectomy. The control pressures were 26 systolic, ten diastolic, and 18 mean. After three minutes of oxygen breathing the pressure had fallen to 19 systolic, eight diastolic, and 14 mean.

A change in the left atrial and pulmonary venous pressure might be a factor of importance in the drop in pulmonary arterial pressure noted in the patients with mitral stenosis. Pulmonary arterial hypertension in these patients may depend upon two factors. The elevated left atrial pressure resulting from the mitral stenosis is transmitted in retrograde fashion through the pulmonary vascular system to the pulmonary artery. Early in the course of mitral stenosis this is the only factor causing increased pulmonary arterial pressure. Later, many patients develop increased pulmonary arteriolar resistance which is associated with a further rise in pulmonary arterial pressure. This increased resistance may be the result of pathological changes in the small vessels or it may be due to vasoconstriction. Oxygen breathing might decrease the pulmonary arterial pressure in patients with mitral stenosis by reducing the pressure in the left atrium or by a vasodilatory effect on the pulmonary vessels. The decreased cardiac rate induced by oxygen breathing permits better left ventricular filling and thus increases the stroke output of that chamber, resulting in turn in a decrease of the left atrial, pulmonary capillary and pulmonary arterial blood volumes and pressures. The relative importance of a decrease in left atrial pressure and the dilatation of the pulmonary vessels might be evaluated by determination of the effect of oxygen breathing on the pulmonary "capillary" pressure. However, it must first be proved that the pressure obtained through a catheter wedged in the pulmonary arterial tree truly reflects the pulmonary venous pressure in patients who have pulmonary vascular changes.

That a decrease of left atrial pressure plays any part in the patients with pulmonary tuberculosis seems unlikely. In this group the pulmonary arterial pressures were normal or slightly elevated and there was no evidence of cardiac involvement. Euler and Liljestrand found that a drop in pulmonary arterial pressure in cats occurred with no change in left atrial pressure (1). 
Because the range of pulmonary arterial pressures and arterial oxygen saturations in the tuberculosis group is not sufficiently great, no conclusions can be drawn as to what part anoxia may play in pulmonary arterial hypertension.

Although a majority of the patients in the pulmonary tuberculosis group had normal or only slightly elevated pulmonary arterial pressures, the tuberculous involvement was with few exceptions rather extensive. Pulmonary vascular changes have been reported in many of these individuals (21). Since it has been shown that oxygen breathing caused a statistically significant decrease in pressure in 14 patients with normal control pressures, the possibility exists that a similar decrease would occur in normal individuals.

It is recognized that significant differences exist between physiologic conditions at the altitude of Denver and those at sea level. The mean annual barometric pressure in Denver is $628 \mathrm{~mm}$. $\mathrm{Hg}$ and the arterial oxygen tension is accordingly somewhat lower here. This somewhat lower oxygen tension may result in a greater degree of tonic activity of the chemoreceptors than exists at sea level. The effect of oxygen breathing on pulse rate, cardiac output and pulmonary vasculature might therefore be more evident in Denver. Possibly the effect of oxygen at this altitude is to abolish the slight relative anoxemia which normally exists here. If this is the case one might observe a less marked response at sea level or even no response at all (8).

The beneficial effect of oxygen therapy on patients with acute or chronic pulmonary arterial hypertension may depend not only upon the factors of increased arterial oxygen tension, decreased cardiac output, and decreased cardiac rate, but also upon a decreased pulmonary arterial pressure, a factor which would further reduce the work of the right ventricle.

\section{SUM MARY}

The effect of breathing $100 \%$ oxygen on the pulmonary arterial pressure in patients with pulmonary tuberculosis and mitral stenosis was studied 52 times in 38 patients.

1. Out of 27 studies in patients with pulmonary tuberculosis, 22 showed a decrease of the pulmonary arterial pressure with oxygen. This decrease was shown to be statistically significant.

2. Out of 25 studies in patients with mitral stenosis, 21 showed a decrease in pulmonary arterial pressure with oxygen. This decrease was shown to be statistically significant.

3. There was a definite correlation between the control mean pulmonary arterial pressure and the degree of its decrease.

4. The factors which may be involved in the observed decrease of pulmonary arterial pressure during oxygen breathing are discussed.

\section{REFERENCES}

1. v. Euler, U. S., and Liljestrand, G., Observations on the pulmonary arterial blood pressure in the cat. Acta physiol. scandinav., 1946, 12, 301.

2. Liljestrand, G., Regulation of pulmonary arterial blood pressure. Arch. Int. Med., 1948, 81, 162.

3. Nisell, O. I., Effects of oxygen and carbon dioxide on the circulation of isolated and perfused lungs of cats. Acta physiol. scandinav., 1948, 16, 121.

4. Nisell, O. I., The action of oxygen and carbon dioxide on the bronchioles and vessels of the isolated perfused lungs. Acta physiol. scandinav., 1950, 21, Suppl. 73.

5. Motley, H. L., Cournand, A., Werko, L., Himmelstein, A., and Dresdale, D., The influence of short periods of induced acute anoxia upon the pulmonary artery pressures in man. Am. J. Physiol., 1947, $150,315$.

6. Doyle, J. T., Wilson, J. S., and Warren, J. V., Effect of hypoxia on pulmonary vascular pressures in man. Federation Proc., 1951, 10, 37.

7. Westcott, R. N., Fowler, N. O., Scott, R. C., Hauenstein, V. D., and McGuire, J., Anoxia and human pulmonary vascular resistance. J. Clin. Invest., 1951, 30, 957.

8. Duke, H. N., Pulmonary vasomotor responses of isolated perfused cat lungs to anoxia and hypercapnia. Quart. J. Exper. Physiol., 1951, 36, 75.

9. Logaras, G., Further studies on the pulmonary arterial blood pressure. Acta physiol. scandinav., 1947, 14, 120.

10. Peters, J. P., and Van Slyke, D. D., Quantitative Clinical Chemistry. Williams \& Wilkins, Baltimore, 1932, Vol. 2.

11. Roughton, F. J. W., and Scholander, P. F., Microgasometric estimation of the blood gases. 1. Oxygen. J. Biol. Chem., 1943, 148, 541.

12. Whitehorn, W. V., Edelmann, A., and Hitchcock, F. A., The cardiovascular responses to the breathing of 100 per cent oxygen at normal barometric pressure. Am. J. Physiol., 1946, 146, 61.

13. Otis, A. B., Rahn, H., Brontman, M., Mullins, L. J., and Fenn, W. O., Ballistocardiographic study of 
changes in cardiac output due to respiration. J. Clin. Invest., 1946, 25, 413.

14. Dripps, R. D., and Comroe, J. H., Jr., The effects of the inhalation of high and low oxygen concentrations on respiration, pulse rate, ballistocardiogram, and arterial oxygen saturation (oximeter) of normal individuals. Am. J. Physiol., 1947, 149, 277.

15. Katz, L. N., Hamburger, W. W., and Rubinfeld, S. H., Observations on the effects of oxygen therapy. II. Changes in circulation and respiration. Am. J. M. Sc., 1932, 184, 810.

16. Anthony, A. J., Uber Sauerstoffatmung. Deutsche med. Wchnschr., 1940, 66, 482.

17. Dautrebande, L., and Haldane, J. S., The effects of respiration of oxygen on breathing and circulation. J. Physiol., 1921, 55, 296.
18. Alveryd, A., and Brody, S., Cardiovascular and respiratory changes in man during oxygen breathing. Acta physiol. scandinav., 1948, 15, 140.

19. Watt, J. G., Dumke, P. R., and Comroe, J. H., Jr., Effects of inhalation of 100 per cent and 14 per cent oxygen upon respiration of unanesthetized dogs before and after chemoreceptor denervation. Am. J. Physiol., 1942-43, 138, 610.

20. Hickam, J. B., and Cargill, W. H., Effect of exercise on cardiac output and pulmonary arterial pressure in normal persons and in patients with cardiovascular disease and pulmonary emphysema. J. Clin. Invest., 1948, 27, 10.

21. Denst, J., Hurst, A., and Dressler, S. H., A histologic study of the blood vessels in surgically resected tuberculous lungs. Am. Rev. Tuberc., 1951, 64, 489. 